\title{
Adição de etanol como coadjuvante no processo de inativação de micro-organismos de ostras em dióxido de carbono supercrítico (scCO2)
}

\author{
D. Soares ${ }^{1}$, L. A. Lerin ${ }^{1}$, A. P. T Zimann ${ }^{1}$, A. R.Monteiro ${ }^{1}$, J. V. OLIVEIRA ${ }^{1}$ \\ ${ }^{1}$ Universidade Federal de Santa Catarina, Departamento de Engenharia Química e Engenharia de \\ Alimentos \\ E-mail para contato: douglas_soares@outlook.com
}

\begin{abstract}
RESUMO - $\mathrm{O} \mathrm{CO}_{2}$ supercrítico tem sido apontado como alternativa para a inativação de micro-organismos em alimentos. Porém, o tempo de processo é considerado longo. Para reduzir o tempo uma alternativa é o uso de coadjuvantes como o etanol, que possui efeito bactericida. Nesse sentido, o presente estudo avaliou a influência da adição de diferentes concentrações de etanol no processo de inativação de micro-organismos de ostras em meio supercrítico. As condições operacionais estudadas foram tempo de processo de 120 min., a temperatura de $33^{\circ} \mathrm{C}$ ciclo de pressão de $80-200-80$ bar, razão massa/massa ostras/scCO2 de 1:08 e taxa de pressurização/despressurização de 100 bar.mim-1. As concentrações de etanol testadas foram $0,1 \% ; 0,25 \% ; 0,5 \%$ e $1 \%$. A condição experimental em que $0,5 \%$ de etanol foi adicionado apresentou uma redução de 4,10 Log (redução total) na contagem de aeróbios mesófilos, enquanto o controle (0\% de etanol) apresentou redução de 1,23 Log dos 4,09 Logs iniciais.
\end{abstract}

\section{INTRODUÇÃO}

Ostras (Crassostrea gigas)são moluscos bivalves, que obtêm seu alimento através da filtração da água onde são cultivadas. A microbiota presente nas ostras costuma refletir as condições do ambiente de cultivo, podendo ser influenciada pela qualidade, temperatura e salinidade da água de cultivo. Esses fatores, aliados à tradição de consumir a ostra crua, tornam a ostra uma potencial ameaça à saúde pública.

Desta forma, a utilização de processos não térmicos, como a utilização do dióxido de carbono supercrítico, surge como alternativa aos métodos convencionais, buscando garantir a qualidade microbiológica das ostras, aumentando sua vida útil e preservando suas características físicas e sensoriais desejadas.

Bi et al. (2011) avaliaram o efeito do tratamento com $\mathrm{CO}_{2}$ pressurizado na inativação da microbiota naturalmente presente em cenouras frescas fatiadas. Para condições experimentais de 50 bar, $20^{\circ} \mathrm{Ce}$ tempo de 20 minutos foram obtidas reduções de 1,86 Log para a contagem de aeróbios e 1,25 Log na contagem de bolores e leveduras.

Liaoet al. (2007) estudaram o processo de inativação de E. coliinoculado em suco de maçã não clarificado utilizando $\mathrm{CO}_{2}$ pressurizado. As condições utilizadas foram 200 bar e $37^{\circ} \mathrm{C}$ e 300 bar a $42^{\circ} \mathrm{C}$ e verificou-se que a inativação da $E$. coliaumentou significativamente com o aumento do tempo de processo. 
Matos e colaboradores (Patente 2013 NBR1020140041729) estudou a utilização de dióxido de carbono supercrítico na inativação de Aeróbios Mesófilos, Vibriosp. eVibrioparahaemolyticuspresentes em ostras, obtendo uma redução de 95,04\% na contagem de $V$. parahaemolyticus.

O etanol possui conhecido efeito bactericida. Furukawa e Hayakawa (2000) estudaram os efeitos do etanol sobre a inativação de esporos de Bacillusstearothermophilus IFO 12550 em um tratamento com calor e pressão moderadamente altos. Setlowet al.(2002) relataram que a combinação de etanol e de calor teve efeitos de inativação leves sobre esporos bacterianos.

Este trabalho tem como objetivo avaliar o efeito da adição de etanol no processo de inativação de micro-organismos em ostras associadoação do $\mathrm{CO}_{2}$ supercrítico.

\section{MATERIAIS E METODOS}

\subsection{Preparação das Amostras}

As ostras foram adquiridas de uma empresa local e transportadas em sacolas isotérmicas até o LATESC - UFSC. Posteriormente as ostras foram lavadas em água corrente e escovadas para a retirada de sujidades presentes na concha. Seguido da abertura das mesmascom faca especifica e a retirada da parte cárnea do molusco,que posteriormente foi ao líquido intervalvar em um béquer previamente higienizado e sanitizado.

Para cada experimento foi utilizado uma dúzia de ostras. Após a abertura de todas as ostras, o conteúdo do béquer foi processado em um liquidificar por 3 minutos, também previamente higienizado e sanitizado. Em seguida, foram retiradas alíquotas de $10 \mathrm{~mL}$ da amostra homogeneizada, usando seringas descartáveis e armazenadas sob refrigeração $\left(7^{\circ} \mathrm{C}\right)$ até a inserção na célula de alta pressão.

\subsection{Aparato Experimental}

Os experimentos foram realizados em uma célula de alta pressão com visualização através de janela de safira, baseado no método estático sintético. O diagrama esquemático do aparato experimental pode ser visualizado na figura 1 e é formado basicamente pela célula de alta pressão, construída em aço inox 316, com volume máximo em torno de $27 \mathrm{~mL}$, encamisada para manutenção das condições experimentais (temperatura). A pressão do sistema foi monitorada por um transdutor de pressão absoluta (Smar LD 301), acoplado a um programador portátil (Smar, HT 201) e uma bomba de seringa (ISCO 260D). A célula possuium pistão móvel, de montagem manual, que tem a função de controlar a pressão interna da célula e, sem permitir a troca de fluidos entre a parte anterior e posterior ao mesmo. 


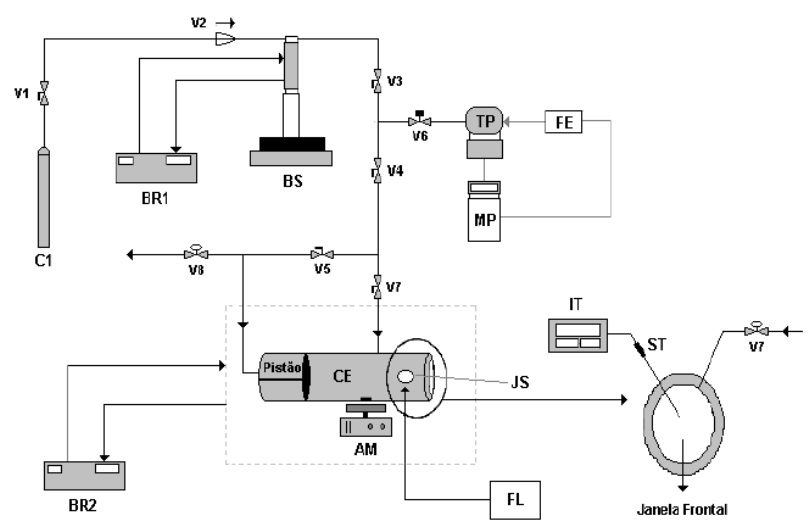

Figura 1 - Diagrama esquemático do aparato experimental utilizado.

\subsection{Procedimento Experimental}

Foi injetado 10 gramas de amostra de ostra processada no interior da célula, com ajuda de uma seringa estéril. Em seguidafoiadicionadoà célula etanol (etanol absoluto PA.)nas concentrações de $0,1 \%-0,25 \%$ - 0,5\% - $1 \%$ (massa/massa).

Posteriormente a célula foi conectada na unidade experimental, e a mesma programadapara iniciar o ciclo de pressurização e despressurização.

Os experimentos seguiram as condições estudadas por Soares et al. (2013) e Matos et al(2013) com2 horas de duração, temperatura igual a $33^{\circ} \mathrm{C}, 1$ ciclo de pressurização/despressurização, razão massa/massa entre ostra processada e $\mathrm{CO}_{2}$ de 1:08 e taxa de despressurização de 100 bat. $\mathrm{mim}^{-1}$.

Imediatamente após o término de cada experimento, realizou-se a análise microbiológica de Aeróbios mesófilos totais, Víbriosp. eV. parahaemolyticus.

\subsection{Análises Microbiológicas Pós-Experimentos}

Contagem total de aeróbios mesófilos totais:Ao término de cada experimento retirou-se uma alíquota de $3 \mathrm{~mL}$ de amostra da célula, na capela de fluxo laminar e realizou-se a diluição da mesma em água peptonada $0,1 \%$ para posterior plaqueamento em meio Ágar Luria Bertani (Ágar LB, composição: triptona 10,0 g/L, extrato de levedura 5,0 g/L, NaCl 5,0 g/ L, ágar 20g/L) estéril.

As placas foram incubadas por 24 horas à temperatura de $37^{\circ} \mathrm{C}$. Após esse período realizou-se a contagem dos micro-organismos Aeróbios Mesófilos de cada placa, expressos em UFC/mL (A.P.H.A., 2001).

Contagem de Vibriosp. e de Vibrioparahaemolyticus: Imediatamente após o término de cada experimento, retirou-se a amostra da célula, na capela de fluxo, e realizou-se a sua diluição em água peptonada salina $3 \%$ e posterior plaqueamento em meio seletivo ágar TCBS (ágar tiossulfato-citrato-sais de bile-sacarose) estéril. As placas foram incubadas por 24 horas, 
à temperatura de $37^{\circ} \mathrm{C}$, para contagem de Vibriosp. eV. parahaemolyticus, expressos em $\mathrm{UFC} / \mathrm{mL}$.

De acordo com a ficha técnica do fabricante dos meios (Himedia), as colônias com coloração verdes azuladas referem-se ao $V$. parahaemolyticus.

\section{RESULTADOS E DISCUSSÃO}

As contagens de aeróbios mesófilos, de Vibriosp. e de V.parahaemolyticusempregando dióxido de carbono supercrítico com adição de alíquotas de etanol estão representados, respectivamente, na Tabela 1, Tabela 2 e Tabela 3. Os experimentos seguiram as condições estudadas por Soares et al. (2013) e Matos et al. (2013) com temperatura igual a $33^{\circ} \mathrm{C}, 1$ ciclo de pressurização/despressurização, razão massa/massa entre ostra processada e $\mathrm{CO}_{2}$ de 1:08 e taxa de despressurização de 100 bat. mim $^{-1}$.

Observa-se na Tabela 1, que a adição de etanol teve efeitopositivo sobre contagem de aeróbios mesófilos (UFC/mL), sendo que as alíquotas de 0,5 e $1 \%$ apresentaram inativação total dos micro-organismos tendo como ponto de partida $94,13 \%$ de inativação do experimento sem adição de etanol.

Kalil et al. (1994) classifica o álcool etílico com um bactericida rápido, que eliminando também o bacilo da tuberculose, os fungos e os vírus, não agindo, porém, contra os esporos bacterianos. Sua concentração ótima dá-se entre 60 e $90 \%$ por volume e, sua atividade diminuimuito com concentração abaixo de $50 \%$. Suas propriedades são atribuídas ao fato de causarem desnaturação das proteínas quando na presença de água e também ação bacteriostática pela inibição da produção de metabólitos essenciais para a divisão celular rápida.

Tabela 1 - Resultados dos ensaios microbiológicos para a contagem de Aeróbios mesófilos em ostras in natura e ostras submetidas ao processo de inativação de micro-organismos através da ação do $\mathrm{CO} 2$ supercrítico $\left(33^{\circ} \mathrm{C}, 1\right.$ ciclo de pressurização/despressurização, razão massa/massa entre ostra processada e $\mathrm{CO}_{2}$ de 1:08 e taxa de despressurização de 100 bat.mim ${ }^{-1}$ )

\begin{tabular}{ccccccc}
\hline \% etanol & $\mathbf{N}_{\mathbf{0}}$ & $\mathbf{N}$ & $\log \mathbf{N}_{\mathbf{0}}$ & $\log \mathbf{N}$ & $\log \mathbf{N} / \mathbf{N}_{\mathbf{0}}$ & $\mathbf{N}-\mathbf{N}_{\mathbf{0}}(\boldsymbol{\%})$ \\
\hline 0 & 12302 & 724 & 4,09 & 2,86 & $-1,23$ & 94,13 \\
0,1 & 21067 & 700 & 4,32 & 2,85 & $-1,48$ & 96,67 \\
0,25 & 127500 & 5950 & 5,11 & 3,77 & $-1,33$ & 95,33 \\
0,5 & 12600 & 0 & 4,10 & 0 & $-4,10$ & 100 \\
1 & 3500 & 0 & 3,54 & 0 & $-3,54$ & 100 \\
\hline
\end{tabular}

Pode-se observar também nas Tabelas 2 e 3, que adição de $0,5 \%$ e $1 \%$ de etanol massa/massa aos experimentos apresentoua inativação total de Vibriosp e Vibrioparahaemoliticus. 
Tabela 2 - Resultados dos ensaios microbiológicos para a contagem de Vibriosp.em ostras in natura e ostras submetidas ao processo de inativação de micro-organismos através da ação do CO2 supercrítico $\left(33^{\circ} \mathrm{C}, 1\right.$ ciclo de pressurização/despressurização, razão massa/massa entre ostra processada e $\mathrm{CO}_{2}$ de 1:08 e taxa de despressurização de 100 bat.mim ${ }^{-1}$ )

\begin{tabular}{ccccccc}
\hline \% etanol & $\mathbf{N}_{\mathbf{0}}$ & $\mathbf{N}$ & $\log \mathbf{N}_{\mathbf{0}}$ & $\log \mathbf{N}$ & $\log \mathbf{N} / \mathbf{N}_{\mathbf{0}}$ & Redução (\%) \\
\hline 0 & 14454 & 66 & 4,16 & 1,82 & $-2,33$ & 99,54 \\
0,1 & 2143 & 20 & 3,33 & 1,30 & $-2,03$ & 99,06 \\
0,25 & 2377 & 685 & 3,38 & 2,84 & $-0,54$ & 71,82 \\
0,5 & 9650 & 0 & 3,98 & 0 & $-3,98$ & 100 \\
1 & 2540 & 0 & 3,40 & 0 & $-3,40$ & 100 \\
\hline
\end{tabular}

Tabela 3 - Resultados dos ensaios microbiológicos para a contagem de Vibrioparahaemolíticus em ostras in natura e ostras submetidas ao processo de inativação de microorganismos através da ação do $\mathrm{CO} 2$ supercrítico $\left(33^{\circ} \mathrm{C}, 1\right.$ ciclo de pressurização/despressurização, razão massa/massa entre ostra processada e $\mathrm{CO}_{2}$ de 1:08 e taxa de despressurização de 100 bat.mim ${ }^{-1}$ )

\begin{tabular}{ccccccc}
\hline \% etanol & $\mathbf{N}_{\mathbf{0}}$ & $\mathbf{N}$ & $\log \mathbf{N}_{\mathbf{0}}$ & $\log \mathbf{N}$ & $\log \mathbf{N} / \mathbf{N}_{\mathbf{0}}$ & Redução (\%) \\
\hline 0 & 1000 & 50 & 3,00 & 1,69 & $-1,30$ & 95,04 \\
0,1 & 30 & 20 & 1,48 & 1,30 & $-0,18$ & 33,33 \\
0,25 & 413 & 40 & 2,62 & 1,60 & $-1,01$ & 90,31 \\
0,5 & 160 & 0 & 2,20 & 0 & $-2,20$ & 100 \\
1 & 540 & 0 & 2,73 & 0 & $-2,73$ & 100 \\
\hline
\end{tabular}

Park et al. (2012) compararam a eficiência da adição de etanol na inativação de esporos de Alternaria brassicicola (KACC 40036) através da ação de $\mathrm{scCO}_{2}$. Partindo de uma suspenção inicial de esporos de $1 \times 10^{7} \mathrm{UFC} / \mathrm{mL}$, os autores observaram que a adição de etanol (16\%) ao sistema reduziu pela metade, de 90 para 45 minutos o tempo necessário para a inativação completa dos esporos fúngicos.

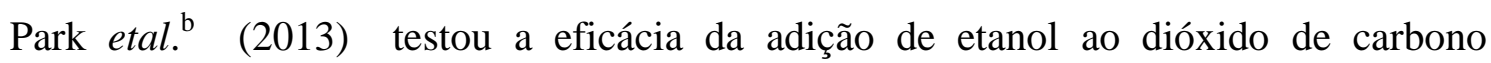
supercrítico na inativação de esporos de Bacilluscereus em biofilmes, cultivados em aço inoxidável. Nos experimentos sem etanol não houve sucesso, utilizando pressões entre $10 \mathrm{e}$ $30 \mathrm{MPa}$, temperatura entre 35 e $60^{\circ} \mathrm{C}$ e tempo entre 10 e $120 \mathrm{~min}$. Quando $10 \mathrm{~mL}$ de etanol foram adicionados como um co-solvente com $\mathrm{scCO}_{2}$, após 90 minutos a $10 \mathrm{Mpa}$ o biofilme foi completamente inativado.

Chianget al. (2006) observou que a população viável de $V$. parahaemolyticus aumentou acentuadamente em TSB-NaCl 3\%, sem etanol, a partir de uma população inicial de 6,0 log ufc/mL a 9,0 log de UFC/mL em 250 minutos. Observou também, que a adição de $2 \%$ de etanol não apresentou efeito inibidor no crescimento do micro-organismo. Por outro lado, a presença de etanol em TSB-3,0\% de $\mathrm{NaCl}$, resultou numa inibição parcial ou efeito bactericida sobre $V$. parahaemolyticus, dependendo da concentração de etanol utilizada. $\mathrm{O}$ 
etanol, a uma dosagem de $8,0 \%$ exerceu um efeito bactericida sobre o microrganismo de teste. Enquanto em 5\%, o etanol causou inibição parcial do crescimento e redução da taxa de crescimento do micro-organismo.

\section{CONCLUSÕES}

A adição de etanol, nas concentrações estudadas, mostrou efeito positivo no processo de inativação de micro-organismos de ostras através da ação de dióxido de carbono supercrítico.

\section{AGRADECIMENTOS}

Os autores agradecem a CAPES, ao CNPq e a Universidade Federal de Santa Catarina pelo apoio financeiro e bolsas de estudo.

\section{REFERENCIAS}

A.P.H.A. Standard methods for the examination of water and wastewater. 20a. ed. Baltimore: Maryland: American Public Health Association (APHA), American Water Works Association (AWWA) e Water Environment Federation (WEF), 2001.

BI, X.; WU, J.; ZHANG, Y.; XU, Z. \& LIAO, X. High pressure carbon dioxide treatment for fresh-cut carrot slices. InnovativeFood Science \&Emerging Technologies, v. 12, n. 3, p. 298-304, 2011.

CHIANG, M-L., HO, W-L., CHOU, C-C.Response of Vibrio parahaemolyticus to ethanol shock.Food Microbiology,v. 23, p. 461-467, 2006.

FURUKAWA, S., HAYAKAWA, I. Investigation of desirable hydrostatic pressure required to sterilize Bacillus stearothermophilus IFO 12550 spores and its sterilization properties in glucose, sodium chloride and ethanol solutions. FoodResearchInternational, v. 33, p. 901-905, 2000.

KALIL, E. M., COSTA, A. J. F. Desinfecção e esterilização. ACTA ORTOP BRAS OUT/DEZ, v. 4, 1994.

LIAO, H.; HU, X.; LIAO, X.; CHEN, F. \& WU, J. Inactivation of escherichia coli inoculated into cloudy apple juice exposed to dense phase carbon dioxide. InternationalJournalofFoodMicrobiology, v. 118, n. 2, p. 126-131, 2007.

MATOS, K. H. O. Inativação microbiana em ostras (Crassostrea gigas) empregando dióxido de carbono supercrítico. 2013. Tese (Doutorado em Engenharia de Alimentos) Universidade Federal de Santa Catarina, Florianópolis, 2013. 
PARK, H. S., CHOI, H. J., KIM, K. H. Inactivation of Alternariabrassicicola spores by supercritical carbon dioxide with ethanol entrainer. Journal of Microbiological Methods v. 88, p. $185-187,2012$.

PARK, H. S., CHOI, H. J., KIM, M-D., KIM, K. H. Addition of ethanol to supercritical carbon dioxide enhances the inactivation of bacterial spores in the biofilm of Bacillus cereus. International Journal of Food Microbiology, v. 166, p. 207-212, 2013.

SETLOW, B., LOSHON, C.A., GENEST, P.C., COWAN, A.E., SETLOW, C., SETLOW, P. Mechanisms of killing spores of Bacillus subtilis by acid, alkali and ethanol. Journal of Applied Microbiology,v.92, p. 362-375, 2002.

SOARES, D., LERIN, L. A., CANSIAN, R. L., OLIVEIRA, J. V., MAZUTTI, M.A. Inactivation of Listeria monocytogenes using supercritical carbon dioxide in a highpressure variable-volume reactor. Food Control, v. 31, p. 514-518, 2013. 